\title{
Further investigation of lameness in cows at pasture: An analysis of the lesions found in, and some possible risk factors associated with, lame New Zealand dairy cattle requiring veterinary treatment
}

\author{
K. E. Lawrence, ${ }^{*}$ R. N. Chesterton, $†$ and R. A. Laven ${ }^{\star 1}$ \\ *Institute of Veterinary and Biomedical Sciences, Massey University, Private Bag 11222, Palmerston North, New Zealand 4442 \\ †Inglewood Veterinary Services, Kelly St., Inglewood, New Zealand 4330
}

\begin{abstract}
Previous descriptive analysis of data collected from veterinary visits to lame cows in the Taranaki region of New Zealand between December 1995 and July 2007 showed an association between both breed and age and lesion type and site. However, that simple analysis had significant limitations as it did not take account of more than 2 factors at the same time and did not evaluate the effect of time (either year or season). This analysis was designed to overcome those limitations. First, correspondence analysis, a multivariate method of analysis, was used to simultaneously evaluate the relationship between the 3 most commonly recorded causes of lameness (i.e., white line disease, sole injury, and axial disease, all of which are diseases of the claw horn), and 4 groups of predictor variables: foot (front or hind), breed (Jersey or Friesian), age (heifer or cow), and claw (lateral or medial). Second, time series analysis was used to ascertain the effect of season on lesion type and identify the change over years in proportional morbidity. The correspondence analysis clearly separated the 3 diseases, showing that differences between these 3 diseases in their risk factors and their etiology. Each disease clustered with a group of predictor variables. White line disease was linked to lateral claw, hind foot, cow, and Friesian breed; sole injury was linked to heifer and medial claw; and axial disease to Jersey and front foot. As sole injury and axial disease are diseases that occur principally in cows at pasture, this is the first full analysis of risk factors for those diseases. The time series analysis further strengthened the conclusion that these 3 diseases have different risk factors, as, even in the strongly seasonal New Zealand system, significant differences in seasonality occurred between them. This analysis adds further to the data which show that claw horn diseases have different etiologies and need to be treated separately for both research purposes and for
\end{abstract}

Received July 22, 2010.

Accepted February 14, 2011.

${ }^{1}$ Corresponding author: r.laven@massey.ac.nz lameness management on-farm. This analysis is only a starting point; more research is required, particularly longitudinal studies, to better understand the differences in etiology between the main causes of lameness due to claw horn disease, especially in cows kept at pasture, so that we can better target prevention.

Key words: lameness, dairy cattle, time series, correspondence analysis

\section{INTRODUCTION}

Lameness has a major effect on the productivity of dairy cattle (Peeler et al., 1994) and also causes significant suffering and compromises their welfare (Laven et al., 2008). Based on a descriptive analysis of 4,488 veterinary treatments for lameness, Chesterton et al. (2008) concluded that the most common cause of lameness in dairy cows in New Zealand was white line disease ( $42 \%$ of diagnoses at first examination), with the second most common being sole injury (29\%), and the third axial disease (13.1\%). That study also showed a significant effect of age on the proportional morbidity of each lesion type and on lesion distribution. Lame cattle in their first lactation (heifers) had an increased proportion of sole injury and a decreased proportion of white line disease and axial disease compared with older cows. They also had a higher proportion of lesions in the front foot (44\% compared with $29 \%$ for older cows). This change was particularly marked for white line disease; $54 \%$ of heifers with white line disease were primarily lame in the front foot compared with only $16 \%$ of older cows. Chesterton et al. (2008) also found a significant effect of breed on relative proportional morbidity, with a higher proportion of lameness in Jersey cattle being due to sole injury, axial wall disease, and footrot than in Friesians, and a lower proportion due to white line disease.

These conclusions were based on a relatively simple analysis which included a maximum of 2 factors (e.g., age and affected foot) in any analysis. This sort of descriptive analysis can provide a valuable overview of a data set; however it is limited in the number of associa- 
tions that can be detected and enumerated. More complex analyses can identify associations between factors more effectively and provide a more rigorous scrutiny of the data. This is essential if we are to understand the etiology of lameness better and to make farm-specific decisions on lameness control.

This study was designed to overcome the limitations of the simple descriptive analysis reported by Chesterton et al. (2008). The first analysis used was multiple correspondence analysis; a weighted principal components analysis of a contingency table. Each row and column is represented by a point in a Euclidean space determined from cell frequencies. Perpendicular factorial axes are then created, which account for as much of the variability in the original predictor variables as possible. The result is a low (often 2) dimensional scatterplot that identifies clusters of predictors that are closely associated, with clusters further from the intersection of the axes having stronger associations.

The main objective of correspondence analysis, therefore, is to produce a visual summary of the complex relationships that exist among a set of categorical predictor and outcome variables (Dohoo et al., 1997). Correspondence analysis gives greater confidence that detected associations are real than does univariate or bivariate analysis. For example, in a study of proportional morbidity such as this one, all cows will have disease. Thus, an apparent breed effect on proportion of disease caused by a specific lesion may be because of a direct breed effect or because of a breed effect on another lesion. For example, Chesterton et al. (2008) showed that, of the lame cows presented for treatment, Jersey cows were more frequently diagnosed with sole injury than Friesians; this may be because Friesians are more prone to white line disease (decreasing the frequency of diagnoses of sole injury) or because Jersey cattle are more prone to sole injury (or a combination of both). The descriptive analysis cannot differentiate between these effects, but multiple correspondence analysis can, because it shows how the predictor variables are related to each other and how clusters of predictor variables are then related to the outcome of interest (Dohoo et al., 2003).

One key factor excluded from the original analysis by Chesterton et al. (2008) was the effect of time, with neither the effect of season nor the effect of year being included. The second analysis used in the present study was a time series analysis, which evaluates the effect of time on the ordering of the data. We have previously used time series analyses of veterinary treatments for lameness in UK dairy cattle (Laven and Lawrence, 2006) and shown that such analyses can add significantly to our understanding of disease epidemiology by identifying seasonal effects, short-term and long-term
Table 1. Data collected for each case of lameness

\begin{tabular}{ll}
\hline Item & Description \\
\hline Date & Date cow treated \\
Age $^{1}$ & Heifer $^{2}$ or adult cow \\
Breed $^{3}$ & Crossbreed recorded as breed that cow most resembled \\
Visit $^{4}$ & First visit or re-examination of recently treated cow \\
Foot & Hind or front \\
Claw & Medial or lateral \\
Disease & As diagnosed by R. N. Chesterton on-farm \\
\hline
\end{tabular}

${ }^{1}$ Not recorded routinely until January 1998.

${ }^{2}$ Not recorded routinely until May 2002.

${ }^{3}$ Lactating cow in its first lactation.

${ }^{4}$ Cow recorded as repeat visit if it had been treated for lameness within $28 \mathrm{~d}$.

trends, and step changes, as well as by highlighting differences between diseases that are thought to have similar etiologies. This paper thus describes how the application of correspondence and time series analysis to the data set described by Chesterton et al. (2008) increases our understanding of the etiology of lameness in New Zealand dairy cattle.

\section{MATERIALS AND METHODS}

The data used for this analysis were collected during veterinary visits to treat lame cows in North Taranaki. All diagnoses, treatments and records were made by one veterinarian (R. N. Chesterton) as part of his normal veterinary practice routine. Data were collected over the period from December 1995 to February 2007, except for the period from December 1999 to March 2002 when R. N. Chesterton was not in New Zealand. The pertinent information collected for each case is summarized in Table 1. Only cases recorded as first visit were used in this analysis.

\section{Lesion Definitions}

For these additional analyses, 4 lesion categories were identified:

1) White line disease (WLD): lesions of the white line (the junction of the coronary wall horn and the horn of the sole), usually involving abscessation and spread toward the heel or the coronary band;

2) Sole injury: lesions which primarily involved the sole horn. These ranged from sole bruising (hemorrhages in the horn) through to sole penetration by foreign bodies and sole abscesses. This category does not include classical sole ulcer, which is a specific sole lesion with a circumscribed zone of localized hemorrhage and necrosis, usually located in the sole/bulb junction in the region of 
the flexor process of the distal phalanx (Weaver et al., 2005) and which causes $<2 \%$ of lameness in New Zealand cattle (Chesterton et al., 2008);

3) Axial wall lesions: lesion or injury involving the development of a fissure in the axial groove or axial wall of the hoof;

4) Other: foot lesions which were less commonly observed than those in categories 1 to 3 [see Chesterton et al. (2008) for further details].

The same diagnostic criteria were used throughout the whole reported period. Only one disease diagnosis was used per case in this analysis. So for cattle with more than one lesion on the same foot, only the most significant lesion was recorded and included in the analysis, whereas for cattle that were lame on more than one foot at the time of examination, the lesion identified as the cause of lameness of the lamest foot was used.

\section{Statistical Analysis}

Data collected during the study were recorded and maintained in a Microsoft Excel spreadsheet (Microsoft Corp., Redmond, WA). All statistical analyses were completed using SAS version 9.1 (SAS Institute, Cary, $\mathrm{NC})$.

Correspondence Analysis. The 3 most common lesion categories were used in this analysis: WLD, sole injury, and axial disease. These outcome variables were then analyzed with 4 groups of predictor variables: foot (front or hind), breed (Jersey or Friesian), age (heifer, i.e., animal in its first lactation, or cow) and claw (lateral or medial). Only cases for which all predictor variables were recorded were included in this analysis.

Time Series Analysis. Time series plots were constructed for the total lameness consultations, for the proportion of total lameness consultations that were due to WLD, axial disease, sole injury, and other diagnoses, and the proportion of treatments that were in hind feet and in heifers. A trend line was fitted to the time series plots to summarize the direction and rate of change in a data series. The trend lines were calculated in PROC AUTOREG (SAS) with dummy variables fitted for each month and December as the reference month. The significance of the time series interruption, from December 99 to March 2002, was tested using the Chow statistic (Chow, 1960). The Chow statistic uses an $F$-test to determine if the coefficients from 2 regression analyses, one from before the interruption and one from after, are the same. A quartic root transformation was used to stabilize the variance of the total lameness treatments. In all cases $P=0.05$ was used as the cut-off point for statistical significance.
The seasonality of the data was examined by constructing boxplots of treatments by month for all causes of lameness, proportion of WLD, axial disease, and sole injury. The strength of any observed seasonality was estimated using the coefficient of determination of the autoregressive regression model $\left(\mathrm{R}_{2 \text { Autoreg }}\right)$ as described by Moineddin et al. (2003). The significance of any potential periodicity in the relative frequency of diseases thought to share a common etiology was explored by first de-trending the ratio of sole injury to WLD and the ratio of axial injury to white line and then fitting a linear regression model with the de-trended data as the dependent variable, and with month as the independent variable (again with December as the reference month).

\section{RESULTS}

\section{Correspondence Analysis}

Data from 1,776 cases were used for the correspondence analysis. These were cases of axial disease, WLD, and sole injury, which had a complete record for all predictor variables (breed, foot, age, and claw). The low number relative to the data set used for the descriptive analysis was because the predictor variables were not all recorded routinely until March 2002. Table 2 shows, for each outcome variable, the total number of lameness cases used in the correspondence analysis and the number and percentage of those cases attributable to each of the 3 outcome variables.

Figure 1 is the map of the multiple correspondence analyses. The first dimension of the analysis accounted for a very large proportion of the inertia or variation in the data present in the original correspondence table $(86.9 \%)$. The correspondence analysis can be read at 3 levels. Reading from left to right, along the $\mathrm{x}$-axis of Figure 1 the first dimension strongly differentiates between the 2 categories for each of the 4 predictor variables (i.e., front vs. hind foot, lateral vs. medial claw, Jersey vs. Friesian, and heifer vs. cow; i.e., each category is on the opposite side of the vertical dotted line originating from the zero point on the $\mathrm{x}$-axis). A similar examination of the outcome variables (the disease types) shows that dimension 1 clearly differentiates between WLD and the other 2 diseases, sole and axial. Reading from top to bottom along the y-axis, the second dimension discriminates most obviously between sole and axial disease - they are clearly on the opposite side of the horizontal dotted line originating from the zero point on the y-axis. Finally, the association between the predictor variables and the outcome variables can be assessed. Examining the lower left quadrant of Figure 1 first, axial disease is strongly associated with Jersey and front feet. Progressing anticlockwise, WLD 
Table 2. Relationship between the predictor variables and the outcome variables used in the correspondence analysis $^{1}$

\begin{tabular}{lrrrr}
\hline & \multicolumn{3}{c}{ Outcome variable } & \\
\cline { 2 - 3 } $\begin{array}{l}\text { Predictor } \\
\text { variable }\end{array}$ & Axial (\%) & Sole (\%) & WLD (\%) & Total \\
\hline Foot & $126(23.7)$ & $226(42.6)$ & $179(33.7)$ & 531 \\
$\quad$ Front & $116(9.3)$ & $373(30.0)$ & $756(60.7)$ & 1,245 \\
Hind & $123(12.1)$ & $224(22.0)$ & $670(65.9)$ & 1,017 \\
Claw & $119(15.7)$ & $375(49.4)$ & $265(34.9)$ & 759 \\
$\quad$ Lateral & $173(11.7)$ & $472(31.9)$ & $834(56.4)$ & 1,479 \\
$\quad$ Medial & $69(23.2)$ & $127(42.8)$ & $101(34.0)$ & 297 \\
Breed & & & & \\
$\quad$ Friesian & $208(14.4)$ & $446(30.9)$ & $788(54.6)$ & 1,442 \\
Jersey & $34(10.2)$ & $153(45.8)$ & $147(44.0)$ & 334 \\
$\quad$ Cow & Heifer & &
\end{tabular}

${ }^{1}$ The outcome variables are the 3 most common causes of lameness identified on-farm when the cows were presented for lameness treatment. Axial = axial disease; sole $=$ sole injury; WLD $=$ white line disease.

straddles the boundary between the next 2 quadrants and is closely associated with Friesian, hind feet, cow, and lateral claws, and the final quadrant shows that sole damage is associated with medial claws and heifers

\section{Time Series Analysis}

Figure 2 shows the time series for all lameness examinations, with the total number of reports for each month plotted against the month and year of treatment. No significant trend over time was observed in the number of lameness treatments per month $(P=0.23)$. The Chow statistic indicated that the interruption in the time series due to the absence of $\mathrm{R}$. N. Chesterton was significant $(P=0.03)$. A dummy variable was fitted to the model with a value of 1 for each month in the time period after the interruption; this was significant $(P=$ $0.03)$ and indicated that, on average, an extra 8.6 lame cows were treated per month after the interruption.

Figure 3 shows the proportion of lameness that was diagnosed as WLD. Over the period from 1995 to 2007 an increase occurred in the proportion of lameness cases diagnosed as being due to WLD $(P<0.001$, regression coefficient $=0.002$ ), an increase of $2.5 \%$ per year. The Chow statistic was not significant. No significant change occurred in the proportion of treatments for axial disease or sole injury over the period of recording; however, the proportion of other diseases decreased significantly $(P<0.001$, regression coefficient $=-0.0019$; Figure 4). The proportion of hind feet treated for lameness showed a step. Immediately after the interruption, the proportion of hind feet treatments decreased $10.7 \%$ (Chow statistic $P<0.02$ ) and then returned to preinterruption levels, with an average $3 \%$ increase each year (Figure 5).

The seasonality of treatments for total lameness, and proportion of WLD, sole injury, and axial disease are all shown in Figure 6. The total lameness treatments are clearly seasonal and the proportion of treatments for WLD hovers around 0.35 to 0.45 , with a clear decrease over May, June, July, and August. The $\mathrm{R}_{\text {Autoreg }}^{2}$ for total lameness, and proportion of WLD, axial disease, and sole injury were $0.46,0.37,0.18$, and 0.23 , respectively. This suggests that, whereas the first 2 conditions show moderate seasonality, axial disease and sole injury were

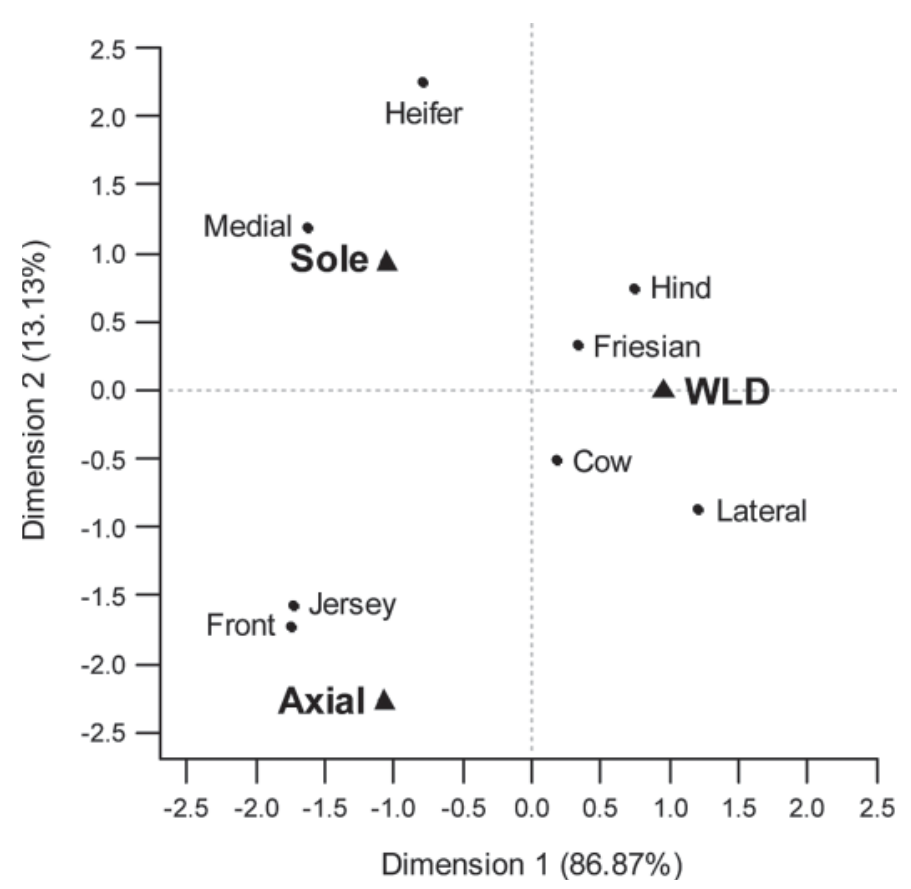

Figure 1. Map of multiple correspondence analysis results. Both the predictor variables (in normal text) and the 3 outcome variables (in bold) are plotted on the first 2 dimensions. The figure in parentheses for each of the dimensions is the proportion of the variance explained by the original correspondence table accounted for by each dimension. Sole $=$ sole injury; $\mathrm{WLD}=$ white line disease; Axial $=$ axial disease. 


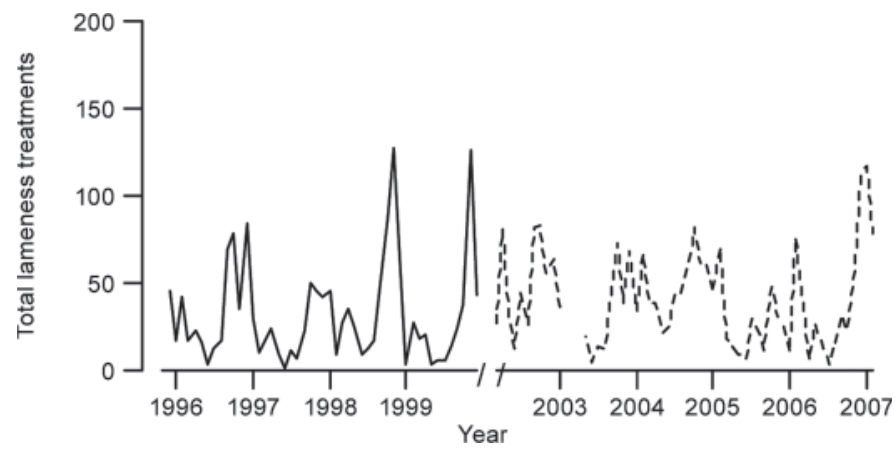

Figure 2. Time series of total monthly lameness examinations by R. N. Chesterton from December 1995 to December 1999 (solid line) and from March 2002 to February 2007 (broken line). The break in the $\mathrm{x}$-axis represents the interruption in the data collection when $\mathrm{R} . \mathrm{N}$. Chesterton was overseas.

only weakly seasonal. Relative to WLD, sole injury was more commonly reported in May, July, August, and September $(P<0.05)$, whereas axial disease reports peaked in August and September $(P<0.05$; Figure 7). Figure 8 shows some seasonality in hind leg treatments $\left(\mathrm{R}_{\text {Autoreg }}^{2}=0.37\right)$ with a decrease over the spring period (July to September) for the proportion of hind leg lameness.

Age of cow (i.e., heifer or older cow) was not routinely recorded until 2002. Nevertheless, the time series analysis from 2002 to 2007 showed a significant decrease in the proportion of treated cattle that were heifers over that period (regression coefficient $=-0.0025, P=$ 0.01 ) from an average of around $30 \%$ in 2002 to $<20 \%$ by 2007. Figure 8 shows some seasonality in heifer treatments with an increase over the autumn/winter period (March to June) for the proportion of heifer-tocow treatments.

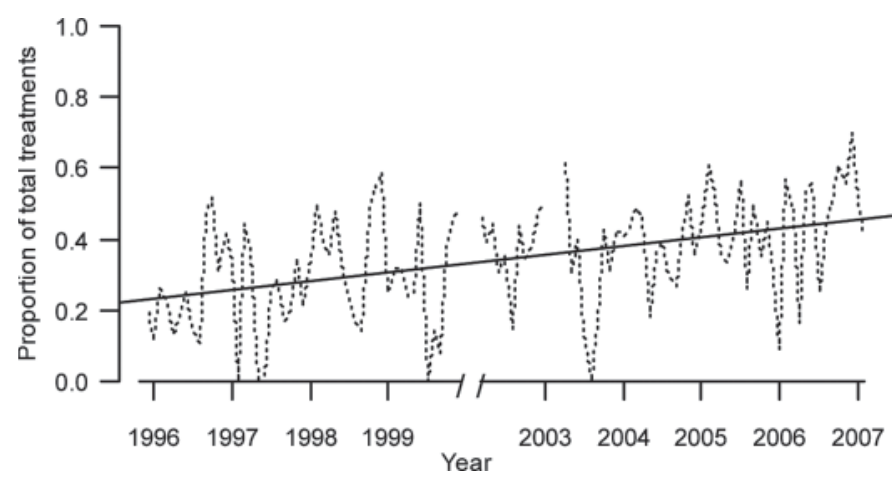

Figure 3. Time series of white line disease diagnoses as a proportion of total lameness treatments in the periods from December 1995 to December 1999 and from March 2002 to February 2007 (dotted line) with fitted regression line (solid line). The break in the $\mathrm{x}$-axis represents the interruption in the data collection when R. N. Chesterton was overseas.

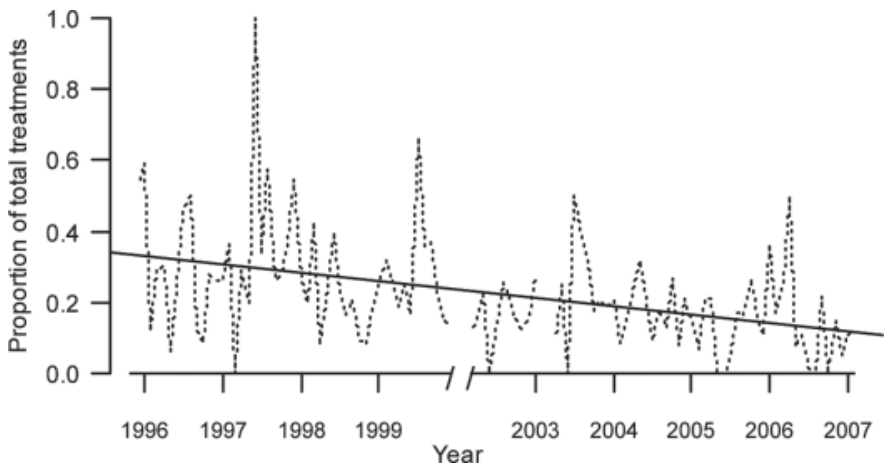

Figure 4. Time series of other diagnoses as a proportion of total lameness treatments in the periods from December 1995 to December 1999 and from March 2002 to February 2007 (dotted line) with fitted regression line (solid line). The break in the $\mathrm{x}$-axis represents the interruption in the data collection when R. N. Chesterton was overseas.

\section{DISCUSSION}

The New Zealand dairy industry is based on the conversion of pasture into milk. Thus, it is highly seasonal - the vast majority of cows in this study would have calved between July and November - and cattle are not normally housed. Thus, the risk factors for lameness and the seasonality of disease may be different in nonseasonal systems that use housing. This may limit the applicability of our findings to other systems, but not the utility of the analytical methods, which we have used for data from other countries.

The data set used in this analysis is highly biased, being the treatment records of a single veterinarian, collected without probabilistic sampling and with no denominator data recorded. Furthermore, they are records from one area with a relatively fixed population of farms. However, long-term, large-scale data on

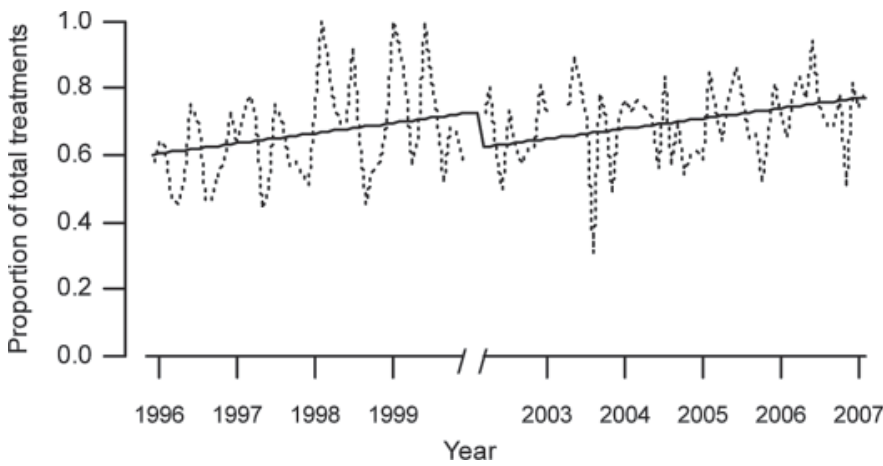

Figure 5. Time series of hind foot lameness as a proportion of total lameness treatments in the periods from December 1995 to December 1999 and from March 2002 to February 2007 (dotted line) with fitted regression line (solid line). The break in the x-axis represents the interruption in the data collection when R. N. Chesterton was overseas. 
a)

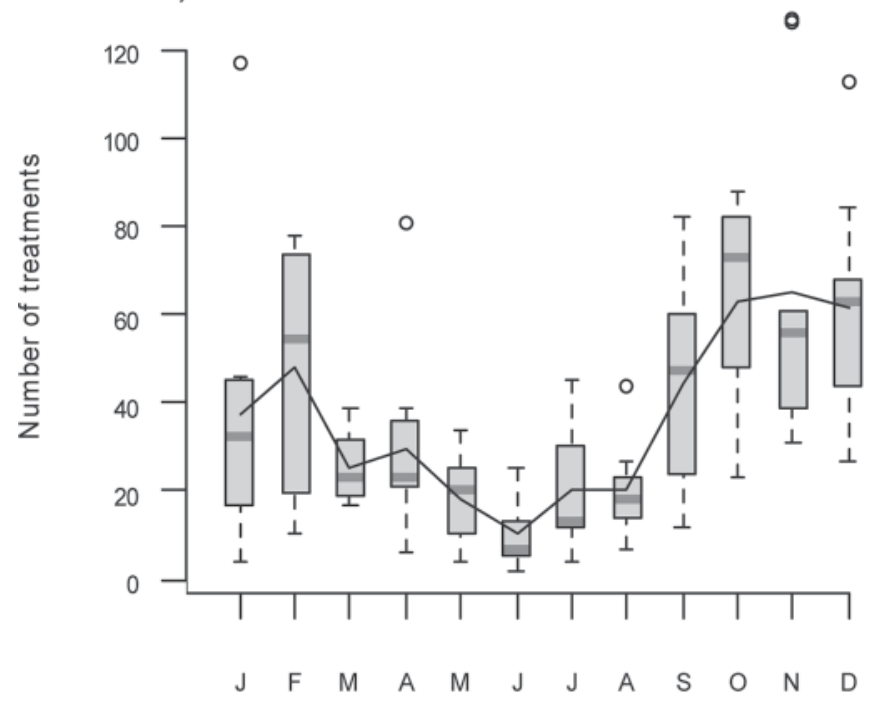

c)

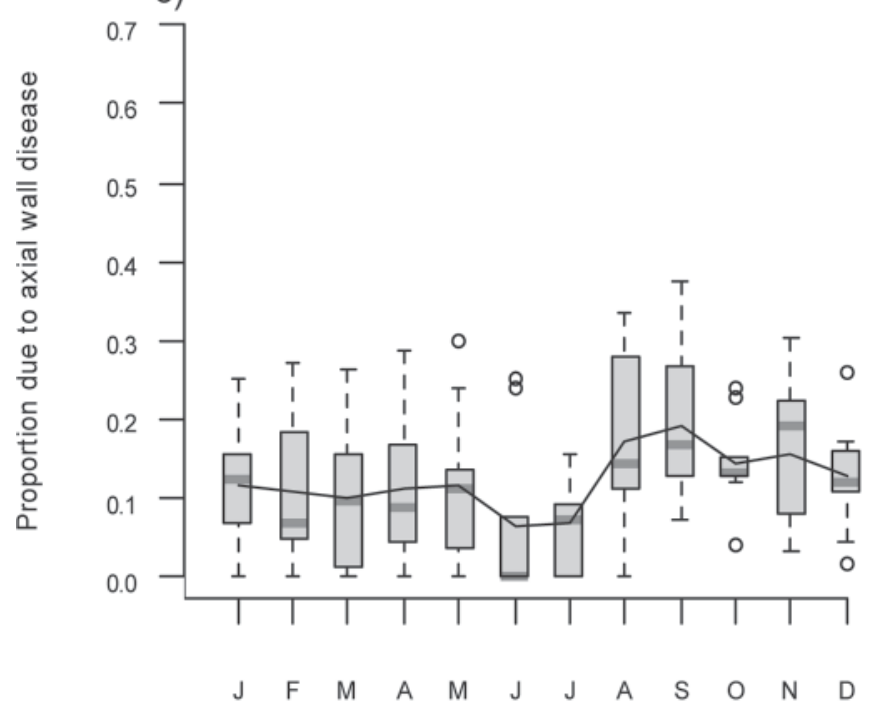

Month b)
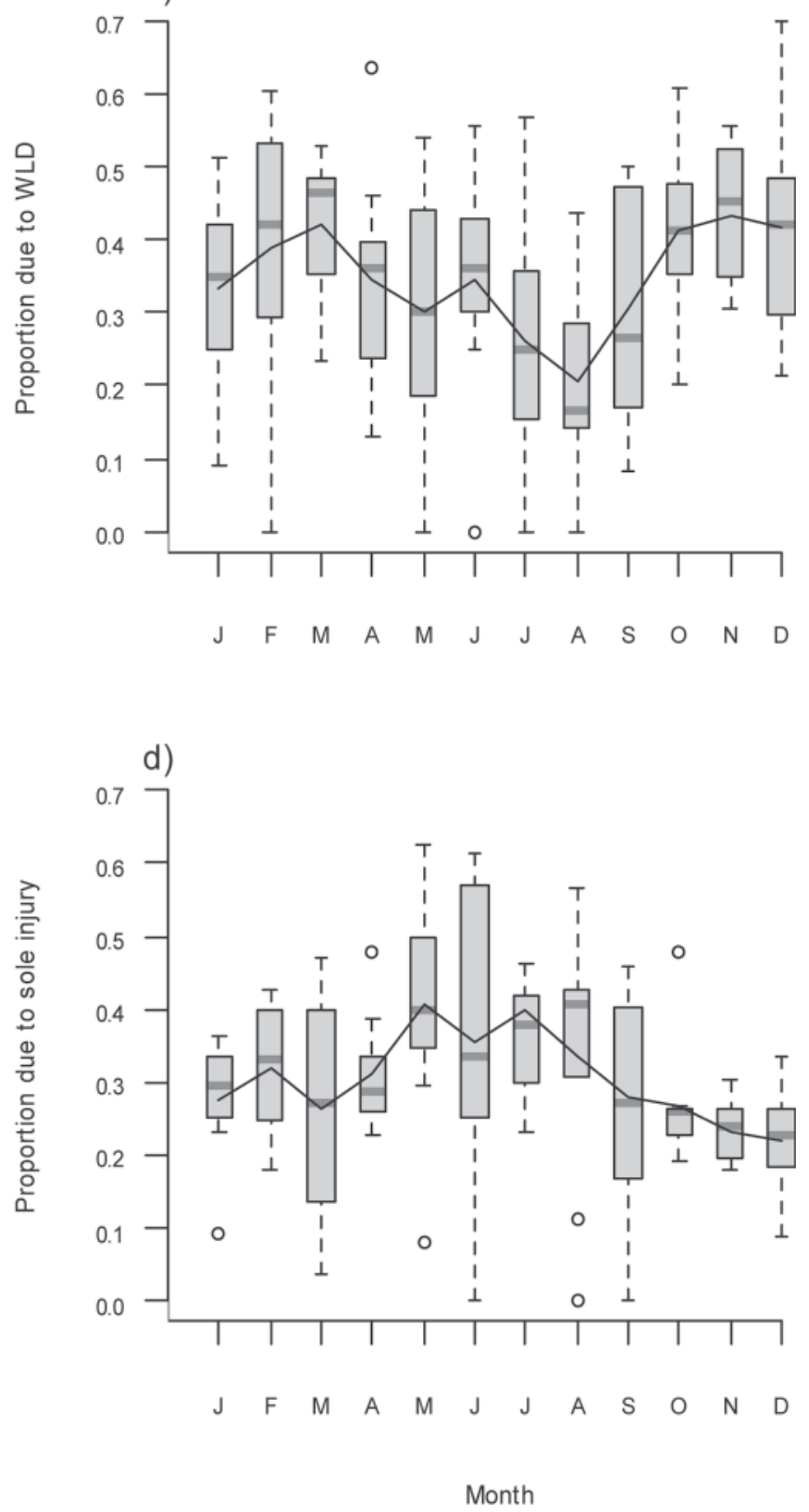

Figure 6. Boxplots of treatments by month for total lameness (a), proportion due to white line disease (WLD; b), proportion due to axial disease (c), and proportion due to sole injury (d) over the survey period. The solid black line is the average number of treatments per month.

lameness is lacking, so even with these reservations we believe this data set is of significant value. The alternative, a large-scale survey of lameness prevalence with a fixed denominator, is much more expensive and does not produce data over the long-term but tends to be a snapshot of 1 or 2 years' worth of data (e.g., Hedges et al., 2001; Gibbs and Laporte, 2008). Furthermore, subsequent large-scale surveys in the same country tend not to cover the same areas as previous surveys (e.g., Murray et al., 1996; Hedges et al., 2001), which hinders comparisons as much as the lack of a denominator does in this case. So, long-term collection and analysis of lameness data from one area is worthwhile, even without a clearly defined denominator. Furthermore, for this analysis, no assumptions were made on the basis of the denominator being constant. The correspondence analysis has no relation to prevalence but simply identifies associations between predictor and outcome variables, whereas the time series analysis compares proportional morbidity in this data set and 
a)

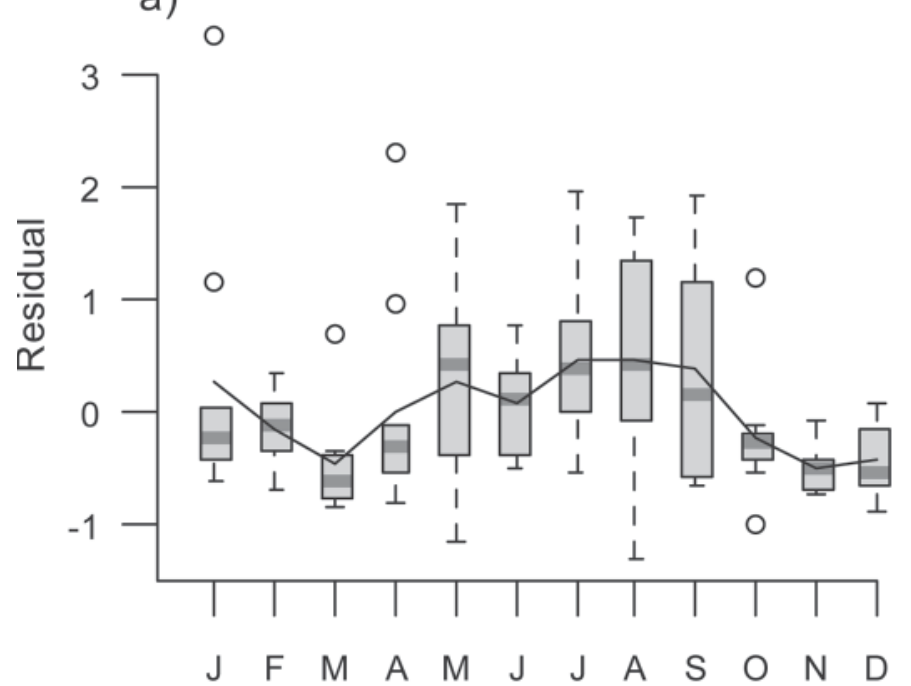

b)

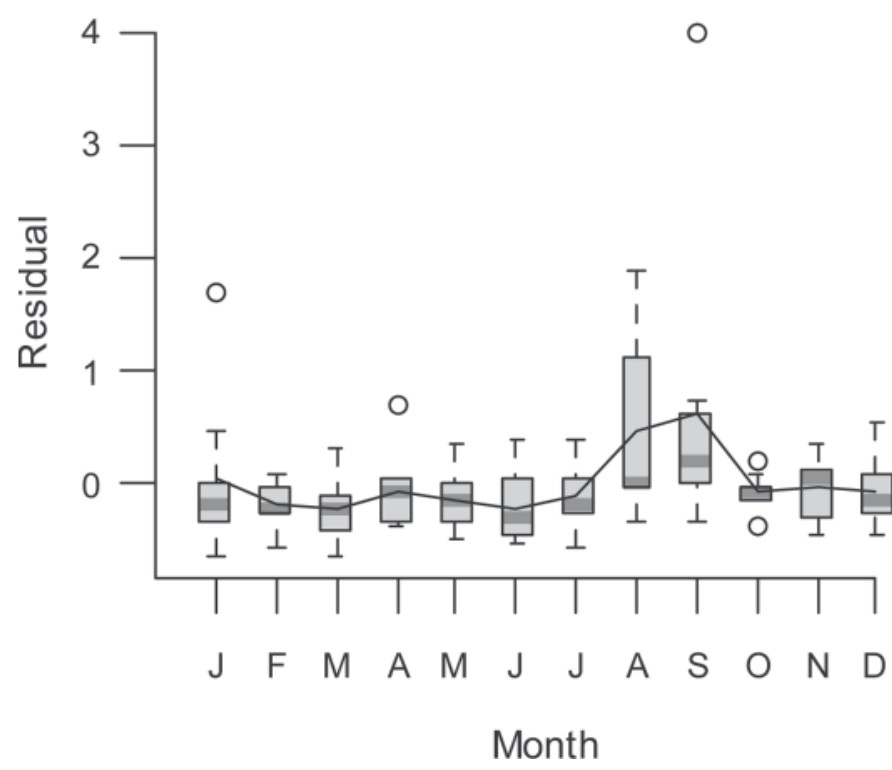

Figure 7. Boxplots of the residuals for sole injury relative to white line disease (WLD) treatments (a) and axial disease relative to WLD (b) by month. The solid black line is the average residual per month.

makes no claims as to whether actual prevalence of disease has changed. A further potential bias is that only one disease diagnosis was used per case, with only one lesion being recorded if there was more than one on the same foot, or more than one foot was affected. However, under New Zealand conditions, multiple lesions on the same foot are very rare, as conditions such as heel horn erosion, and digital and interdigital dermatitis, which are often found in combination with other causes of lameness (Holzhauer et al., 2008), are absent or rare (Chesterton et al., 2008). Furthermore less than $10 \%$ of a)

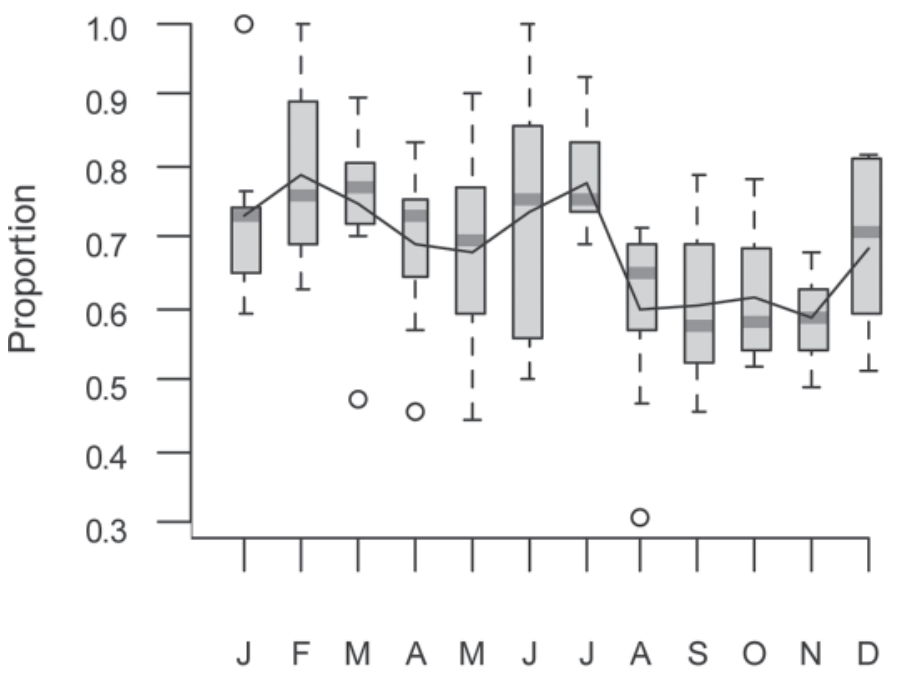

b)

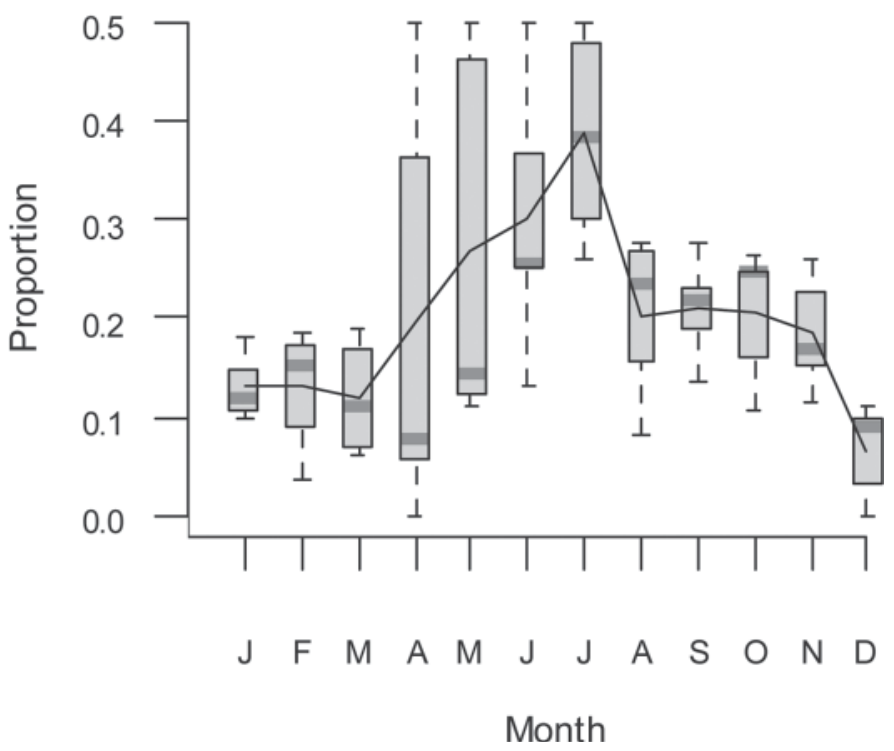

Figure 8. Boxplots of treatments by month for proportion of hind foot lameness (a) and proportion of heifer treatments (b). The data for plot (b) are from 2002 to 2007 only.

lame cows in this study were lame on more than one foot; of these, $70 \%$ had WLD on the lamest foot, and of those, $78 \%$ had lesions of WLD on both feet. Overall, $<25 \%$ of cows with 2 lame feet had a different diagnosis on the less lame foot, equivalent to $<2.5 \%$ of diagnoses.

We thus believe that the conclusions from this analysis should act as a starting point for guiding further research on lameness under New Zealand conditions and a stimulus for identifying similar patterns in other dairying areas, as well as a demonstration of the im- 
portance of proper recording of lameness in identifying the main risk factors on farm. Too often, veterinary management of lameness involves merely treating a long series of individual cows, when what is needed is a holistic overview of the problem and its management. Without proper recording this cannot occur.

This analysis has significantly enhanced the value of this data set. First, the correspondence analysis has clarified and expanded the results from our descriptive analysis. The separation by dimension 1 of WLD from sole and axial disease clearly shows that WLD has risk factors that are different from those for sole and axial disease. The latter 2 diseases were pulled apart by dimension 2, showing that these 2 diseases have, at least, some different risk factors. However, as they were separated only by dimension 2, which accounted for $13 \%$ of the inertia, the difference between these 2 diseases is much less than that between them and WLD. These differences are further illustrated by the clustering of the predictor variables around the 3 diseases.

In this study, axial disease was associated with Jersey breed and front feet; this means that the proportion of axial disease was higher than expected in front feet and in Jersey cattle, indicating that, in this population, Jersey cattle had a higher risk of axial disease than did Friesians and front feet had a higher risk than back feet. For multiple correspondence analysis only interpretation from predictor to outcome variable is valid, the opposite is not. So although a cow that is lame in the front foot has a higher risk of axial disease than one that is lame in the back feet, it doesn't mean that axial disease is necessarily more common in front feet-indeed, as Table 2 shows, cases of axial disease are almost equally common in back and front feet. This is because the simple comparison does not take into account the fact that overall, the risk of lameness is greater in hind feet than in front feet. Similarly, more cases of axial disease were seen in Friesians because more of the cattle in this population were Friesian.

For axial disease, published comparisons of the risk factors for this disease with those for others lesions are very limited, as, although it is occasionally reported elsewhere, axial disease seems to be a significant cause of lameness only in systems where cattle are kept at pasture throughout the year, such as in New Zealand and parts of Australia. So, whereas Jubb and Malmo (1991) reported that $21.7 \%$ of the lameness they treated in dairy cattle in the Australian state of Victoria was caused by axial lesions and McLennan (1988) reported a proportional morbidity of $8.4 \%$ in dairy cattle from Queensland, Eddy and Scott (1980) reported that that only $2.9 \%$ of the lame cattle they treated in Somerset, United Kingdom had axial lesions (recorded as medial sand cracks), whereas such lesions were not even a cat- egory in the study of lame cows in the UK reported by Murray et al. (1996), or in the study from the southeastern United States reported by Sanders et al. (2009). Jubb and Malmo (1991) recorded both lesion type and affected hoof and claw, and so do provide some comparative data. Of the 653 lame cows they treated, 150 had axial disease, of which $65 \%$ were in the hind limbs, higher than the $48 \%$ reported in this study, but increased risk of axial disease still occurred in the front feet, as the proportion of foot lameness in the hind foot, excluding axial disease, was $73 \%$. In regard to affected claw, although Jubb and Malmo (1991) reported that $80 \%$ of axial disease was in the lateral claw (compared with the $51 \%$ in this data set), this was not significantly different from the proportion of all lameness (excluding axial disease) in the lateral claw, so, as in this study, no evidence was found that claw was a predictor for axial disease.

The identification of the link between the Jersey breed and axial disease strengthens the conclusion from our descriptive analysis, and this is the first time that a link between breed and axial disease has been demonstrated. This finding of an increased risk of axial disease in Jerseys is in contrast to most published analyses of breed and overall lameness, which have shown a link between Holstein-Friesians and similar breeds and risk of lameness. For example, Barker et al. (2010) reported that herds which had no Holstein-Friesian cattle tended to have decreased lameness prevalence compared with herds consisting entirely of Holstein-Friesians. Our finding emphasizes the multi-factorial nature of lameness and that the effect of breed on lameness may not be consistent across all types of lameness.

The 2 predictor variables which clustered with sole disease were medial claw and heifer, confirming the conclusion of the descriptive analysis that sole lesions were linked to medial claws and that heifers have a greater risk of developing sole disease than cows. Again the caveats of interpolating backward need to be stressed, as Table 2 shows that sole lesions were more commonly recorded in lame cows than heifers. The absence of a link between sole disease and breed or foot highlights the advantages of multiple correspondence analysis. The proportion of front feet lesions due to sole disease $(42.6 \%)$ was higher than the proportion of hind foot problems that were sole disease (30\%), suggesting a link between front foot lameness and sole disease. However, Figure 1 shows that the separation of sole disease and axial disease by dimension 2 also broke the link between front foot and sole disease, and, similarly, that between the Jersey breed and sole disease. This indicates that the higher proportion of sole injury cases seen in Jerseys and front feet was, at least partly, a statistical artifact due to the decreased proportion of 
WLD reported in Jerseys and front feet, illustrating how a multivariate analysis is better at identifying relationships than a simple univariate or bivariate one.

The relationship between sole lesions and the medial claw has not been reported previously. Vermunt and Greenough (1996) reported that, in housed Canadian heifers, sole hemorrhages were more severe in the medial claws of the front feet than in the lateral hind claws, consistent with the clinical impression that lameness in the front feet tends to be in the medial claw (Blowey, 1993). However, Vermunt and Greenough (1996) found that the level of sole hemorrhage in the lateral hind claws was much greater than that in any medial claw. This is supported by data from the United Kingdom; Le Fevre et al. (2001) showed that not only were sole hemorrhages most severe in the lateral claws of the hind limb but the difference between the lateral hind claws and the other claws was greater for sole than white line hemorrhages. In contrast, sole lesions were more evenly spread across claws and feet than white line lesions in this study. However, comparing sole lesions across housed and pasture-based cattle is complicated by the fact that in housed cattle, the major sole-associated lesion is sole ulcer, a site-specific lesion, whereas in pasture-based cattle, the main lesion is sole injury, which can occur at any site in the sole. It is likely that the low incidence of sole ulcer in New Zealand dairy cattle is related to the low use of housing combined with rare use of concentrate feeds (Livesey et al., 2003; Laven and Holmes, 2008) and that, like axial disease, the relatively high level of sole injury seen in this data set and the analyses reported by Jubb and Malmo (1991) and Tranter and Morris (1991) is related to the pasture-based system under which the cows in those studies and the current one were managed. Thus, it may be that the connection between sole lesions and medial claw is also a pasture effect. However, neither Tranter and Morris (1991) nor Jubb and Malmo (1991) reported more sole lesions on the medial than the lateral claw. Of the 78 lame cows that Tranter and Morris (1991) found with sole lesions, 24 (31\%) were in the medial claw; the proportion reported by Jubb and Malmo (1991) was very similar $(53 / 150,35 \%)$. However, differences were found between the studies when this figure was compared with that of WLD. Tranter and Morris (1991) concluded that sole lesions were less likely to be found in the medial claw than WLD (46/73, $37 \%$ ), whereas in Jubb and Malmo (1991), the proportion of sole lesions on medial claws was markedly higher than the proportion in cows with WLD $(3 / 50,6 \%)$. The reasons for the difference between this data set and the 2 previous studies is unclear, but a change in the distribution pattern of sole lesions since the early 1990s may have occurred - for example, in cows on the farms studied by Tranter and Morris (1991), sole lesions are more commonly found in medial claws than is WLD (R. A. Laven, unpublished data).

As the high level of sole injury appears to be a pasture-specific problem, it is also not surprising that the link between heifers and sole injury has not been commonly reported before. The etiology of this link is unclear. Tranter and Morris (1992) suggested that excess wear, particularly of the sole, was responsible for a lot of the lameness seen in pasture-based cattle. It may be that excess wear of the sole is most pronounced in heifers, as a greater change in hoof shape occurs, particularly sole concavity, after calving in heifers than in older cows (Tranter and Morris, 1992). However, this suggestion is not consistent with the link between medial claw and sole disease, as sole wear is greatest in lateral claws (Tranter and Morris, 1992) and, in cows with thin soles, the sole thickness of the medial claw tends to be greater (van Amstel et al., 2004). This would suggest that the effects of thin claws should be seen in the lateral claw rather than the medial one. Indeed, this is the case in housed cows (van Amstel et al., 2004). However, Chesterton (2004) suggested that response to herding pressure (i.e., when cows are pushed together, either on the track or in the collecting yard) may be an important factor in determining the site of lesions. Under such pressure, heifers, and less dominant cows, tend to push backward and away from the source of pressure - other cows, dogs, stock people, or electric fences. Such pressure is likely to be highest in pasture-based cattle, as they have long journeys to be milked when they are in close proximity to and interacting with other cows. If this is the case, then even though the medial claws are thicker, they may be more prone to injury. Further research is required to better understand the pathogenesis of sole injury on dairy farms in New Zealand, particularly the role of hoof conformation and sole thickness.

The remaining 4 predictor variables cluster around WLD, showing that Friesians and cows have a higher risk than expected of WLD and lesions are more likely to be found in the lateral claws and hind feet than expected, consistent with the conclusions from the descriptive analysis. The importance of the lateral hind claw as a site for lameness, particularly WLD, has also been reported by other studies in New Zealand and abroad (Tranter and Morris, 1991; Hedges et al., 2001; Gibbs and Laporte, 2008). The link between Friesian and WLD is consistent with previous reports; Baird et al. (2009) showed that Holstein-Friesians had higher white line lesion scores than did Norwegian genotype cattle across a range of systems from summer grazing to permanent housing, whereas Kujala et al. (2010) showed that Holstein cows were 1.57 times more likely 
than Finnish Ayrshire cows to develop WLD. The reason for this link between breed and the development of WLD is unclear. For example, the relative absence of pigment in the feet of Holstein-Friesians is suggested as a possible cause (Chesterton et al., 1989), but no evidence exists that the lack of pigment is not simply another proxy for breed. For example, Lethbridge et al. (2008) showed that the puncture resistance of hoof horn from Jersey-Friesian cross calves was greater than that from pure Friesians, but further testing showed no evidence that in animals of the same breed, that pigmented horn was stronger (J. Margerison, Massey University, Palmerston North, New Zealand, personal communication). Another alternative is the weight of the cow relative to the surface area of the claw, which tends to be higher in the Holstein-Friesian than in other breeds (Andersson and Lundström, 1981; Baird et al., 2009), but no prospective study of this effect has been published.

So, overall, the correspondence analysis clearly shows that sole disease and axial disease have, at least some, distinctly different risk factors from WLD, and although they are more similar, axial and sole disease have some different risk factors. Sole disease and WLD are commonly thought of as having similar underlying etiologies (Ossent and Lischer, 1998). However, Le Fevre et al. (2001) showed that within each claw, hemorrhages in the sole and hemorrhages in the white line, the precursors to sole and white lesions, were not highly correlated and concluded that the 2 lesion types should be treated as separate entities. The practical effect of this was shown by Hedges et al. (2001) who reported that the risk of WLD but not sole ulcer was decreased by biotin supplementation. Our findings that sole and white line lesions have different risk factors are thus consistent with those of Le Fevre et al. (2001) and Hedges et al. (2001). We also support the conclusion of Le Fevre et al. (2001) that assuming that all claw horn lesions are a single class is an oversimplification, which should be avoided, and that it is important, for both research and practical lameness management on-farm, to record whether the lesions resulting in lameness are in the white line or the sole.

The time series analysis has shown a significant change in the proportional morbidity of the 4 diagnostic groups, with a significant increase in the proportion of lameness diagnoses being WLD and a decrease in the proportion of other diagnoses. The latter change may be due to increased farmer treatment of footrot, which was the most common of the other diagnoses (Chesterton et al., 2008) and which can be treated easily and effectively with a course of parenteral antibiotics. Such a change would mean that at least some of the increase seen in the proportion of lameness due to WLD was not related to an increase in the proportional morbidity of that condition. However, no evidence from this data set indicated any significant decrease in proportional morbidity of footrot $(P=0.67)$, and comparison with previous data from New Zealand, particularly Tranter and Morris (1991), suggests that the increase in the relative proportional morbidity of WLD is real. A data set such as this one cannot conclusively identify the cause of these changes, but the most likely cause of the increased proportion of WLD is an increase in the proportion of Friesian cattle [perhaps linked to an increase in the percentage of North American Holstein-Friesian cows in the population as distinct from the traditional (smaller) New Zealand Friesian], larger herds, and increased time spent standing on concrete. This suggestion is consistent with the increased risk of WLD on South Island farms (60\% of all lameness, Gibbs and Laporte, 2008). South Island herds tend to be larger, spend longer standing on concrete, and have a higher proportion of Friesians than herds in Taranaki (LIC, 2007). Combining the correspondence analysis with the time series suggests that it is likely that the change in relative proportional morbidity of WLD is linked to the decrease in the proportion of lame cows that were heifers. Further research is required to establish whether the decrease in the proportion of lame cows that are heifers is an actual or relative decrease.

Lameness treatment was moderately seasonal, with $>40 \%$ of cases occurring in the 3 -mo period from October to December. This is slightly later than reported by Tranter and Morris (1991). They recorded the majority of lameness in their spring calving herds in September to November, with few cases in December. Furthermore, Tranter and Morris (1991) reported no treatment of lameness during February in either spring- or autumncalving herds, whereas approximately $10 \%$ of lameness treatments occurred in February in the current study. The reason for these differences is unclear. The seasonality of this data set is also different from that reported in the South Island, where the peak months for lameness treatment are December to March, which account for $>70 \%$ of all lameness cases (Gibbs, 2010). The reason for this difference is also unclear. Timing of peak lameness is important, as it is likely that the financial effect of lameness is dependent, in part, on when a cow becomes lame. For example, the costs associated with lameness of a cow that is clinically lame during the breeding season are likely to be higher than that of a cow that becomes lame in February when it is already pregnant.

The comparison between diseases in their seasonality highlights their differences in etiology. Sole injury was less seasonal than the other conditions and the relative proportion of sole injury cases to WLD treatments was 
more variable throughout the year, confirming their different etiologies, as suggested by Chesterton (2004). In particular, sole injury was seen at a higher rate compared with WLD in late winter/early spring (May and July to September). This suggests that the development of sole injury tends to be more acute than that of WLD, with lameness occurring sooner after calving. In contrast, sole lesions in housed cattle - which are precursors to sole ulcers - tend to develop later than white line hemorrhages (Leach et al., 1997), confirming again the difference between sole ulcer and the sole lesions seen in New Zealand dairy cattle.

Treatment of axial disease peaked in August and September relative to WLD, but for the remainder of the year, the ratio was constant. This indicates that the 2 conditions share similar underlying risk factors, but that after calving, axial disease develops at a different rate than does WLD. Cows with axial disease present with a fissure in the horn of the axial hoof wall, usually along the axial groove. This fissure normally extends from the coronary band to around half of the distance to the bearing surface. Often, a protruding area of sensitive tissue is present at, or near, the base of the fissure. It is the movement of the wall horn against the underlying sensitive tissue that causes the clinical lameness. The etiology of the fissure is unclear; it is probably traumatic, with stone impaction thought to be the primary cause (R. N. Chesterton, unpublished data). It is uncertain whether the fissure develops initially because of damage to horn-producing tissue at the coronary band leading to a downwards-growing crack, or whether trauma to the axial groove leads to a split in the horn, which extends upwards to the coronary band. The seasonality data provide no evidence as to which of these theories is correct, as both can potentially fit the data. If the coronary band theory is correct, the increased relative proportion of axial disease in the early post-calving period may be due to cows that had lesions before calving becoming lame once they calve and start walking long distances again, putting pressure on the axial wall. If the split theory is correct, then it suggests that the lag time from insult to pathology (development of a significant split) is shorter than the lag time from initial insult to the development of WLD. The lack of certainty highlights the requirement for a better understanding of the etiology and pathogenesis of axial disease. Interestingly, the ratio of axial to sole was constant all year round with no significant monthly excesses, which could indicate that axial disease is a crossover condition sharing some common etiologies with both WLD and sole.

This further analysis of this large data set has highlighted the usefulness of both correspondence and time series analysis in improving our understanding of en- demic disease. Both analyses have identified significant effects, which were not identified by simple descriptive analysis, and highlighted areas where our current understanding of lameness in dairy cattle in New Zealand is insufficient, as well as the need for future research.

\section{REFERENCES}

Andersson, L., and K. Lundström. 1981. The influence of breed, age, body weight and season on digital diseases and hoof size in dairy cows. Zentralbl. Veterinarmed. A 28:141-151.

Baird, L. G., N. E. O'Connell, M. A. McCoy, T. W. J. Keady, and D. J. Kilpatrick. 2009. Effects of breed and production system on lameness parameters in dairy cattle . J. Dairy Sci. 92:2174-2182.

Barker, Z. E., K. A. Leach, H. R. Whay, N. J. Bell, and D. C. Main. 2010. Assessment of lameness prevalence and associated risk factors in dairy herds in England and Wales. J. Dairy Sci. 93:932941.

Blowey, R. W. 1993. Cattle Lameness and Hoofcare. Farming Press, Ipswich, UK.

Chesterton, R. N. 2004. Linking farm physical conditions, herd management and cow behaviour to the distribution of foot lesions causing lameness in pasture-fed dairy cattle in New Zealand. Pages 189-191 in Proc. 13th Intl. Sym. and 5th Conf. on Lameness in Ruminants, Maribor, Slovenia.

Chesterton, R. N., K. E. Lawrence, and R. A. Laven. 2008. A descriptive analysis of the foot lesions identified during veterinary treatment for lameness on dairy farms in north Taranaki. N. Z. Vet. J. 56:130-138.

Chesterton, R. N., D. U. Pfeiffer, R. S. Morris, and C. M. Tanner. 1989. Environmental and behavioural factors affecting the prevalence of foot lameness in New Zealand dairy herds-A case-control study. N. Z. Vet. J. 37:135-142.

Chow, G. C. 1960. Tests of equality between sets of coefficients in two linear regressions. Econometrica 28:591-605.

Dohoo, I. R., C. Ducrot, C. Fourichon, A. Donald, and D. Hurnik. 1997. An overview of techniques for dealing with large numbers of independent variables in epidemiologic studies. Prev. Vet. Med. 29:221-239.

Dohoo, I. R., W. Martin, and H. Stryhn. 2003. Veterinary Epidemiologic Research. Atlantic Veterinary College Inc., University of Prince Edward Island, Prince Edward Island, Canada.

Eddy, R. G., and C. P. Scott. 1980. Some observations on the incidence of lameness in dairy cattle in Somerset. Vet. Rec. 106:140-144.

Gibbs, S. J. 2010. Dairy lameness in the South Island. Pages 424-427 in Proc. of the 4th Australasian Dairy Science Symposium, Lincoln University, Canterbury, New Zealand.

Gibbs, S. J., and J. Laporte. 2008. Risk factors and incidence of dairy lameness in large herds of the South Island of New Zealand. Pages 169-171 in Proc. 15th Intl. Sym. and 7th Conf. on Lameness in Ruminants, Kuopio, Finland.

Hedges, J., R. W. Blowey, A. J. Packington, C. J. O'Callaghan, and L. E. Green. 2001. A longitudinal field trial of the effect of biotin on lameness in dairy cows. J. Dairy Sci. 84:1969-1975.

Holzhauer, M., C. Hardenberg, and C. J. Bartels. 2008. Herd and cowlevel prevalence of sole ulcers in the Netherlands and associatedrisk factors. Prev. Vet. Med. 85:125-135.

Jubb, T. F., and J. Malmo. 1991. Lesions causing lameness requiring veterinary treatment in pasture fed cattle in East Gippsland. Aust. Vet. J. 68:21-24.

Kujala, M., I. R. Dohoo, and T. Soveri. 2010. White-line disease and haemorrhages in hooves of Finnish dairy cattle. Prev. Vet. Med. 94:18-27.

Laven, R. A., and C. W. Holmes. 2008. A review of the potential impact of increased use of housing on the health and welfare of dairy cattle in New Zealand. N. Z. Vet. J. 56:151-157.

Laven, R. A., K. E. Lawrence, J. F. Weston, K. R. Dowson, and K. J. Stafford. 2008. Assessment of the duration of the pain response associated with lameness in dairy cows, and the influence of treatment. N. Z. Vet. J. 56:210-217. 
Laven, R. A., and K. R. Lawrence. 2006. An evaluation of the seasonality of veterinary treatments for lameness in UK dairy cattle. J. Dairy Sci. 89:3858-3865.

Leach, K. A., D. N. Logue, S. A. Kempson, J. E. Offer, H. E. Ternent, and J. M. Randall. 1997. Claw lesions in dairy cattle: Development of sole and white line haemorrhages during the first lactation. Vet. J. $154: 215-225$.

Le Fevre, A. M., D. N. Logue, J. E. Offer, I. McKendrick, and G. Gettinby. 2001. Correlations of measurements of subclinical claw horn lesions in dairy cattle. Vet. Rec. 148:135-138.

Lethbridge, L. A., J. K. Margerison, G. W. Reynolds, R. Laven, and C. S. Brennan. 2008. Comparison of lameness and hoof horn puncture resistance of New Zealand Friesian and Jersey cross Friesian dairy cattle. Proc. N.Z. Soc. Anim. Prod. 68:128-129.

LIC (Livestock Improvement Corp. Ltd). 2007. New Zealand Dairy Statistics 2006-2007. Livestock Improvement Corp. Ltd., Hamilton, New Zealand.

Livesey, C. T., J. A. Metcalf, and R. A. Laven. 2003. Effect of concentrate composition and cubicle bedding on the development of hoof haemorrhages in Holstein heifers after calving. Vet. Rec. 152:735-739

McLennan, M. W. 1988. Incidence of lameness requiring veterinary treatment in dairy cattle in Queensland. Aust. Vet. J. 65:144-147.

Moineddin, R., R. E. Upshur, E. Crighton, and M. Mamdani. 2003. Autoregression as a means of assessing the strength of seasonality in a time series. Popul. Health Metr. 1:10.
Murray, R. D., D. Y. Downham, M. J. Clarkson, W. B. Faull, J. W. Hughes, F. J. Manson, J. B. Merritt, W. B. Russell, J. E. Sutherst, and W. R. Ward. 1996. Epidemiology of lameness in dairy cattle: Description and analysis of foot lesions. Vet. Rec. 138:586-591.

Ossent, P., and C. J. Lischer. 1998. Bovine laminitis: The lesions and their pathogenesis. In Pract. 20:415-427.

Peeler, E. J., M. J. Otte, and R. J. Esslemont. 1994. Inter-relationships of periparturient diseases in dairy cows. Vet. Rec. 134:129-132.

Sanders, A. H., J. K. Shearer, and A. De Vries. 2009. Seasonal incidence of lameness and risk factors associated with thin soles, white line disease, ulcers, and sole punctures in dairy cattle. J. Dairy Sci. 92:3165-3174.

Tranter, W. P., and R. S. Morris. 1991. A case study of lameness in three dairy herds. N. Z. Vet. J. 39:88-96.

Tranter, W. P., and R. S. Morris. 1992. Hoof growth and wear in pasture-fed dairy cattle. N. Z. Vet. J. 40:89-96.

van Amstel, S. R., J. K. Shearer, and F. L. Palin. 2004. Moisture content, thickness, and lesions of sole horn associated with thin soles in dairy cattle. J. Dairy Sci. 87:757-763.

Vermunt, J. J., and P. R. Greenough. 1996. Sole haemorrhages in dairy heifers managed under different underfoot and environmental conditions. Br. Vet. J. 152:57-73.

Weaver, A. D., G. St. Jean, and A. Steiner. 2005. Bovine Surgery and Lameness. 2nd ed. Blackwell Publishing, Oxford, UK. 